TP Periodica Polytechnica

Transportation Engineering

46(3), pp. 122-128, 2018

https://doi.org/10.3311/PPtr.11635

Creative Commons Attribution (i)

RESEARCH ARTICLE

\section{The Possibility for Implementing the Superstreet Unconventional Intersection Design in Jordan}

\author{
Hana Naghawi ${ }^{1 *}$, Alaa AlSoud ${ }^{2}$, Taqwa AlHadidi ${ }^{3}$
}

Received 21 April 2017; accepted 22 November 2017

\begin{abstract}
This paper provides policy makers with an objective assessment on the possibility for implementing an unconventional arterial intersection design, the Superstreet, for improving safety and operational characteristics for an existing signalized intersection. The signalized intersection selected for analysis was Tabarbour, located in Amman, Jordan. Tabarbour intersection is considered one of the most significant signalized intersections in Amman. The intersection currently suffers from the following problems: long queues, delays and excessive emissions. SYNCHRO microscopic simulation software was used for signal optimization of the current conventional intersection. VISSIM microscopic simulation software was used to analyze and compare the Superstreet design to the conventional design. It was found that the proposed Superstreet reduced the average delay per vehicle by up to $87 \%$ and reduced the maximum queue length by almost 97\%. This resulted in improving the level of service from $F$ to $C$. Finally, five year future traffic demand analysis was performed; it was found that the Superstreet design didn't perform as expected under heavy traffic volume.
\end{abstract}

\section{Keywords \\ Superstreet, Unconventional Arterial Intersection Design, UAID, Microsimulation, VISSIM, SYNCHRO}

${ }^{1}$ Civil Engineering Department, University of Jordan, Amman 11942, Jordan

${ }^{2}$ Taffic Systems Management Division, Traffic Operation Department, Greater Amman Municipality, Amman, Jordan

${ }^{3}$ Virginia| VT, Department of Civil and Environmental Engineering, Blacksburg, VA, 24060, USA

*Corresponding author, e-mail: hana_naghawi@yahoo.com

\section{Introduction}

Transportation agencies and engineers around the world are constantly challenged by the continuous increase in traffic volumes and the resultant congestion at signalized arterial intersections. This traffic congestion is mainly caused by the high left turning traffic volumes, which inversely impacts performance at signalized intersections. Transportation engineers have implemented many conventional measures to ease this problem, such as signal timing optimization, exclusive left turning signal, implementing double left turn lanes, widening intersections, and grade separation, but the use of these conventional measures are limited and expensive (Hummer and Reid, 1999). Therefore, there has been considerable interest in alternative measures to improve performance and safety characteristics at signalized arterial intersections with heavy left turning traffic. The Federal Highway Administration (FHWA, 2004) proposed several unconventional arterial intersection designs (UAIDs). These UAIDs include Bowtie, Continuous Flow Intersection (CFI), Paired Intersection, Jughandle, Median U-Turn (MUT), Single Quadrant Roadway, Superstreet Median Crossover, Continuous Green T, and Parallel Flow Intersection (PFI). Typically, these designs eliminate/reroute conflicting left turning manoeuvres to and from the minor cross road.

Many unconventional intersection design studies are based on theoretical traffic conditions. This leaves policy makers a little worried of its effectiveness under real traffic conditions. The purpose of this paper is to provide policy makers with an objective assessment on reconfiguring an existing intersection in Amman, Jordan into a Superstreet unconventional intersection design. The signalized intersection selected for analysis was Tabarbour signalized intersection. This intersection is considered one of the most significant signalized intersections in Amman. The intersection currently suffers from the following problems: long queue of vehicles, delay and excessive emissions. The existing intersection was modelled using real traffic data. For the purpose of this study the Microscopic simulation softwares VISSIM and SYNCHRO were used to model and compare the existing intersection to the reconfigured Superstreet intersection. The following sections describe the 
information needed to evaluate the Superstreet design. A brief introduction to the selected site and the softwares input data is presented as well.

\section{Superstreet Description}

Fig. 1 shows the vehicular movement at the Superstreet intersection. The Superstreet design is an extension of the Median U-Turn unconventional intersection design. It offers the best conditions for the through movements on the major arterial road. It redirects left turning and through traffic from the minor road onto the major road using a series of coordinated signals. The Superstreet design permits each direction on the major road to operate independently as two separate Tintersections. This means that the Superstreet can operate like a pair of one-way street, and perfect progression is possible at any speed with any signal spacing. This allows traffic signals at the Superstreet intersection to only use two phases compared to four or more phases at the conventional four-legged signalized intersection, which improve the overall operation and safety of the intersection, enhance capacity (with an increase in effective green) and reduce delay (Hummer and Jagannathan, 2008; Minseok et al., 2007; Bared and Kaisar, 2002; Reid and Hummer, 1999; Reid, 2004).

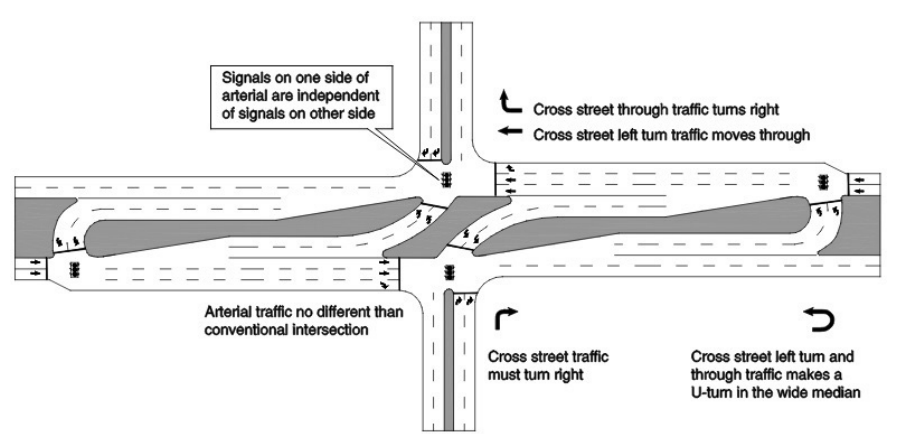

Fig. 1 Superstreet Vehicular Movement (FHWA, 2014)

These capabilities can be considered extraordinary capabilities of the Superstreet UAID. The conventional arterial intersections cannot approach this efficiency even with excruciating control of accesses and signal installations. Finally, the Superstreet intersection design results in a total of 20 conflict points compared to 32 conflict points created by the conventional four-legged signalized intersection (FHWA, 2010).

\section{Previous Findings}

Many researchers have investigated the Superstreet intersection design using different hypothetical traffic data representing different congestion levels, and ignoring other prevailing conditions that might exist at the intersection. Naghawi and Idewu (2014) used CORSIM to compare the operational efficiency of a conventional signalized intersection with an unconventional Superstreet intersection. Several hypothetical scenarios were created by changing the approach volumes and turning percentages on the major and minor roads to reflect different congestion levels at the intersection resulting in a total of 72 scenarios, 36 for the conventional model and 36 for the Superstreet model. It was found that the Superstreet intersection design consistently showed evidence of decreased delay time and queue length when compared to the conventional design. The percent reduction in the network delay ranged from 27.39 to 82.26 percent and the percent reduction in the average network queue length was almost 97.50 percent when the Superstreet design was implemented.

Also, Kim et al. (2007) conducted a study using VISSIM to compare the operation and safety performance of the Superstreet designs to the conventional designs. They analyzed three scenarios of Superstreet design: one left lane and two through lanes on major road, one left lane and three through lanes on major road and two left lanes and three through lanes on major road then, they compared them to the conventional intersection. The results showed that the Superstreet design is similar to the Median U-turn design but has some additional features that allow for through traffic progression on the major road in both directions by preventing the minor road traffic from crossing the major road. Hummer et al. in a report for the FHWA (2010) used VISSIM to assess the operational performance of five geometric design cases, 90 simulation scenarios were done for both designs: Superstreet and comparable conventional intersection designs. It was found that the Superstreet have shorter travel time than the conventional intersection under low minor road volumes compared to total intersection volume (less than 0.25). Hummer et al. (2007) used the critical lane volume procedure to estimate the capacity of the Superstreet. Adjustments to the ideal saturation flow rate were made for trucks, a 2.1 seconds average saturation headway was used to calculate the base critical lane capacity of $1587 \mathrm{pcphpl}$. It was found that the Superstreet can handle major road through volume up to 2,600 vph, major road left turning volume up to $600 \mathrm{vph}$, minor road through volumes up to $900 \mathrm{vph}$, and minor road left turning volume up to $400 \mathrm{vph}$.

Few researchers evaluated the performance of implementing the Superstreet design using real world traffic data. One of them is a study performed in North Carolina. The operational analysis involved creating VISSIM models for three existing Superstreet intersections and comparing them to results from models of equivalent conventional intersections. Significant improvement in traffic performance and safety was found when the Superstreet design was implemented (FHWA, 2010). Another study was done by Jae et al. (2011). They used VISSIM to evaluate the feasibility and possibility for implementing the Superstreet unconventional intersection design on arterial roads in Korea, they found that corridors with Superstreet experienced less delays and performed better than other traditionally operated corridors during peak hour volumes.

Many researchers suggested that safety and operational efficiency are the major benefits of the Superstreet UAID over the 
conventional intersection design. Minseok et al. (2007) found that the Superstreet intersection design can achieve significant reduction in accident frequency and severity, stopped delay and queue length as compared to the conventional intersection design. Also, Hochstein et al. (2009) analyzed crash data from Superstreet intersections in Maryland and North Carolina. One site was converted from two way stopped controlled intersection to a Superstreet intersection. It was found that the Superstreet intersection design reduced crash rate at the main intersection by 92 percent.

\section{Methodology}

\subsection{Site Description}

Fig. 2 shows an aerial photo of the selected intersection: Tabarbour, Tabarbour intersection is located in Amman, the capital city of Jordan. The intersection is controlled by a pretimed traffic signal with a cycle length of 155 seconds. It is considered one the most significant intersections in Amman. The intersection connects the major arterial road: Al Shaheed, with the minor arterial roads: Prince Hamza and Tareq. Al Shaheed road runs East and West bounds of the intersection. It is a four lane divided arterial road with a posted speed of 70 $\mathrm{km} / \mathrm{hr}$. It connects Zaraqa city, the second largest city in Jordan, with Amman. Also, the capital retail, commercial and industrial facilities are located on the road to take advantage of its high traffic volume and connectivity. The east side of the intersection is the entrance to a large residential area. The minor arterial road is composed of Tareq road to the North and Prince Hamza road to the South. Tareq road is a two lane divided minor arterial road with a posted speed of $60 \mathrm{~km} / \mathrm{hr}$. Prince Hamza road is a three lane divided minor arterial road with also a posted speed of $60 \mathrm{~km} / \mathrm{hr}$.

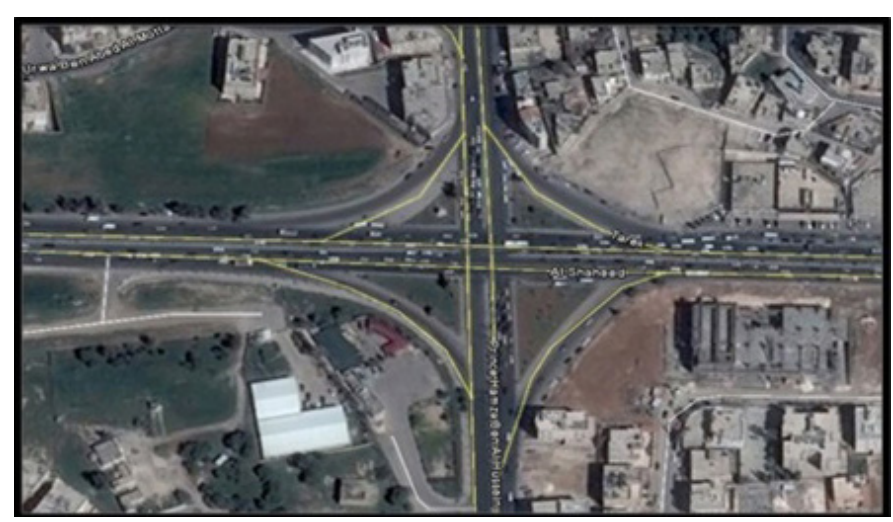

Fig. 2 Aerial Photo of the Selected Intersection

The intersection currently suffers from the following problems:

- Long queue of vehicles on all approaches.

- Enormous delays on all approaches.

- Large amount of emissions which are generated from the acceleration and deceleration of vehicles at the traffic signal.
Transportation engineers at Greater Amman Municipality (GAM) have implemented many conventional measures, to ease the congestion problem at Tabarbour intersection, including: traffic signal coordination with adjacent signalized intersections on the arterial road, increasing the number of signal phases and implementing multiple left and right turning lanes. Unfortunately, these conventional measures did not result in improving traffic performance at the intersection.

\subsection{Data Collection}

Real traffic data were made available by the Department of Traffic Operations at GAM. Traffic volumes including turning movements, were collected at Tabarbour intersection on Monday the $27^{\text {th }}$ of September 2014 at fifteen minute intervals. A sample of the collected traffic volumes is shown in Table 1. It includes the fifteen minute volumes in the evening between $(7: 30-9: 30) \mathrm{pm}$. It can be seen that the major arterial, Al Shaheed, road suffers from high through traffic volumes, while the minor arterial roads, Prince Hamza and Tareq, suffer from high left turning volumes.

Table 1 Traffic Volumes at the Study Area (GAM)

\begin{tabular}{|c|c|c|c|c|c|c|c|c|c|}
\hline \multirow{2}{*}{ Time } & \multicolumn{2}{|l|}{ App. } & \multicolumn{3}{|c|}{ Al Shaheed EB } & \multicolumn{4}{|c|}{ Al Shaheed WB } \\
\hline & Mov. & $\mathrm{R}$ & $\mathrm{T}$ & $\mathrm{L}$ & $\mathrm{U}$ & $\mathrm{R}$ & $\mathrm{T}$ & $\mathrm{L}$ & $\mathrm{U}$ \\
\hline \multicolumn{2}{|c|}{$7: 30-7: 45$} & 95 & 350 & 81 & 7 & 48 & 580 & 97 & 1 \\
\hline \multicolumn{2}{|c|}{$7: 45-8: 00$} & 110 & 379 & 84 & 6 & 54 & 495 & 113 & 14 \\
\hline \multicolumn{2}{|c|}{$8: 00-8: 15$} & 129 & 336 & 72 & 8 & 52 & 472 & 105 & 2 \\
\hline \multicolumn{2}{|c|}{$8: 15-8: 30$} & 131 & 356 & 70 & 7 & 39 & 490 & 53 & 0 \\
\hline \multicolumn{2}{|l|}{ Total } & 465 & 1421 & 307 & 28 & 193 & 2037 & 368 & 17 \\
\hline \multicolumn{2}{|c|}{$8: 30-8: 45$} & 117 & 380 & 35 & 6 & 55 & 576 & 59 & 0 \\
\hline \multicolumn{2}{|c|}{$8: 45-9: 00$} & 92 & 387 & 60 & 7 & 47 & 502 & 76 & 1 \\
\hline \multicolumn{2}{|c|}{$9: 00-9: 15$} & 94 & 367 & 42 & 5 & 25 & 541 & 74 & 1 \\
\hline \multicolumn{2}{|c|}{$9: 15-9: 30$} & 105 & 326 & 62 & 4 & 65 & 595 & 58 & 3 \\
\hline \multicolumn{2}{|l|}{ Total } & 408 & 1460 & 199 & 22 & 192 & 2214 & 267 & 5 \\
\hline \multirow{2}{*}{ Time } & \multicolumn{2}{|l|}{ App. } & \multicolumn{3}{|c|}{ Prince Hamza NB } & & & \multicolumn{2}{|c|}{ Tareq SB } \\
\hline & Mov. & $\mathrm{R}$ & $\mathrm{T}$ & $\mathrm{L}$ & $\mathrm{U}$ & $\mathrm{R}$ & $\mathrm{T}$ & $\mathrm{L}$ & $\mathrm{U}$ \\
\hline \multicolumn{2}{|c|}{$7: 30-7: 45$} & 77 & 141 & 112 & 12 & 46 & 66 & 57 & 6 \\
\hline \multicolumn{2}{|c|}{$7: 45-8: 00$} & 87 & 135 & 160 & 21 & 66 & 56 & 81 & 13 \\
\hline \multicolumn{2}{|c|}{$8: 00-8: 15$} & 72 & 106 & 120 & 27 & 98 & 79 & 81 & 4 \\
\hline \multicolumn{2}{|c|}{$8: 15-8: 30$} & 74 & 81 & 150 & 15 & 96 & 77 & 98 & 9 \\
\hline \multicolumn{2}{|l|}{ Total } & 310 & 463 & 542 & 80 & 306 & 278 & 317 & 32 \\
\hline \multicolumn{2}{|c|}{$8: 30-8: 45$} & 70 & 55 & 110 & 19 & 92 & 62 & 67 & 11 \\
\hline \multicolumn{2}{|c|}{$8: 45-9: 00$} & 78 & 60 & 65 & 12 & 90 & 48 & 96 & 14 \\
\hline \multicolumn{2}{|c|}{$9: 00-9: 15$} & 50 & 84 & 70 & 17 & 80 & 46 & 89 & 2 \\
\hline \multicolumn{2}{|c|}{$9: 15-9: 30$} & 75 & 94 & 75 & 10 & 60 & 60 & 67 & 8 \\
\hline \multicolumn{2}{|l|}{ Total } & 273 & 293 & 320 & 58 & 216 & 216 & 319 & 35 \\
\hline
\end{tabular}




\subsection{Signal Optimization}

The SYNCHRO software, with its capabilities to produced best solutions when delay at signalized intersections is the main objective of signal optimization, was selected to optimize signal phasing and cycle lengths (FHWA, 2002). The SYNCHRO analysis results revealed that for the optimized signal timing of 175 seconds, the conventional intersection suffers from overall intersection delay per vehicle of $199.5 \mathrm{sec} / \mathrm{veh}$, which corresponds to level of service (LOS) F. Table 2 shows the SYNCHRO model results including volume to capacity ratio (v/c), average delay per vehicle and LOS for each movement of the optimized conventional intersection. It can be seen that the $\mathrm{v} / \mathrm{c}$ ratios were higher than one for almost all movements except for the right turning movements since they have an exclusive right turning ramps as shown in Fig. 2. The high v/c ratios imply capacity deficiency and system failure at the intersection. Also, Table 2 shows that the average delay per vehicle ranged from $51 \mathrm{sec} / \mathrm{veh}$ to $672 \mathrm{sec} /$ veh except for the free right turning movements which didn't suffer any mentioned delay. These delay amounts corresponded to breakdown conditions with LOS F.

These results were used for vehicle inputs and routing decisions as well as traffic signal timing in the conventional intersection design in the VISSIM model.

Table 2 SYNCHRO Conventional Model Results

\begin{tabular}{lccc}
\hline Movement & v/c & $\begin{array}{c}\text { Average Delay } \\
\text { (Sec/veh. }\end{array}$ & LOS \\
\hline N-S & 1.14 & 149 & F \\
N-E & 1.13 & 163 & F \\
N-W & 0.26 & 0 & A \\
S-N & 2.42 & 672 & F \\
S-W & 1.66 & 357 & F \\
S-E & 0.35 & 1 & A \\
W-E & 0.81 & 51 & D \\
W-N & 1.09 & 137 & F \\
W-S & 0.35 & 1 & A \\
E-W & 1.17 & 124 & F \\
E-S & 1.42 & 237 & F \\
E-N & 0.17 & 0 & A \\
\hline
\end{tabular}

\subsection{Intersection Design and Model Development}

Microscopic models, for the existing optimized conventional intersection and the proposed Superstreet unconventional intersection design, were developed and tested using VISSIM, microscopic traffic simulation software. Both intersection designs were created in CAD layout then imported into VISSIM software. The design of the conventional and the Superstreet unconventional intersections consisted of a four lane divided major arterial road intersecting with a three lane and a two lane divided minor arterial roads that replicate the existing Tabarbour intersection. The Superstreet intersection was designed to match the configuration shown in Fig. 1. Only one "four-phase" signal was required for the existing conventional intersection model, while four "two-phase" signals had to be modelled on the proposed Superstreet unconventional model. Two were placed at the main intersection and two were placed at the U-turns. Fig. 3 and Fig. 4 show snapshots of the VISSIM simulation for the existing conventional and the proposed Superstreet unconventional intersection designs respectively.

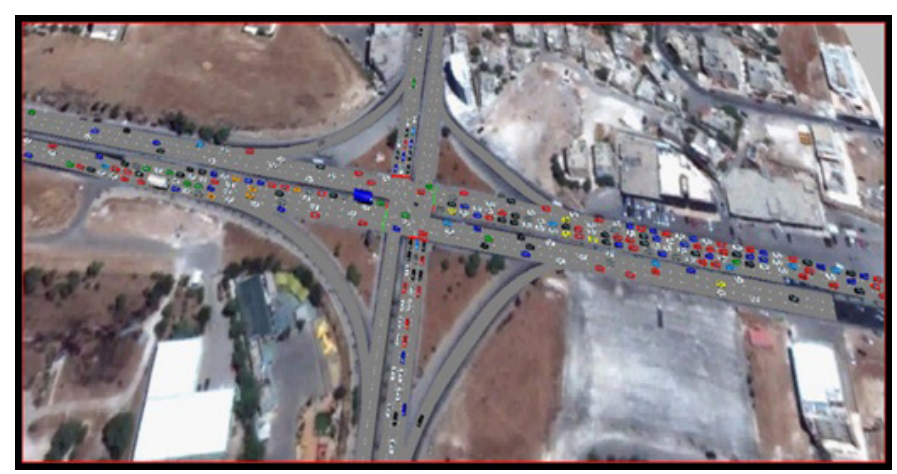

Fig. 3 VISSIM Simulation for the Existing Conventional Intersection

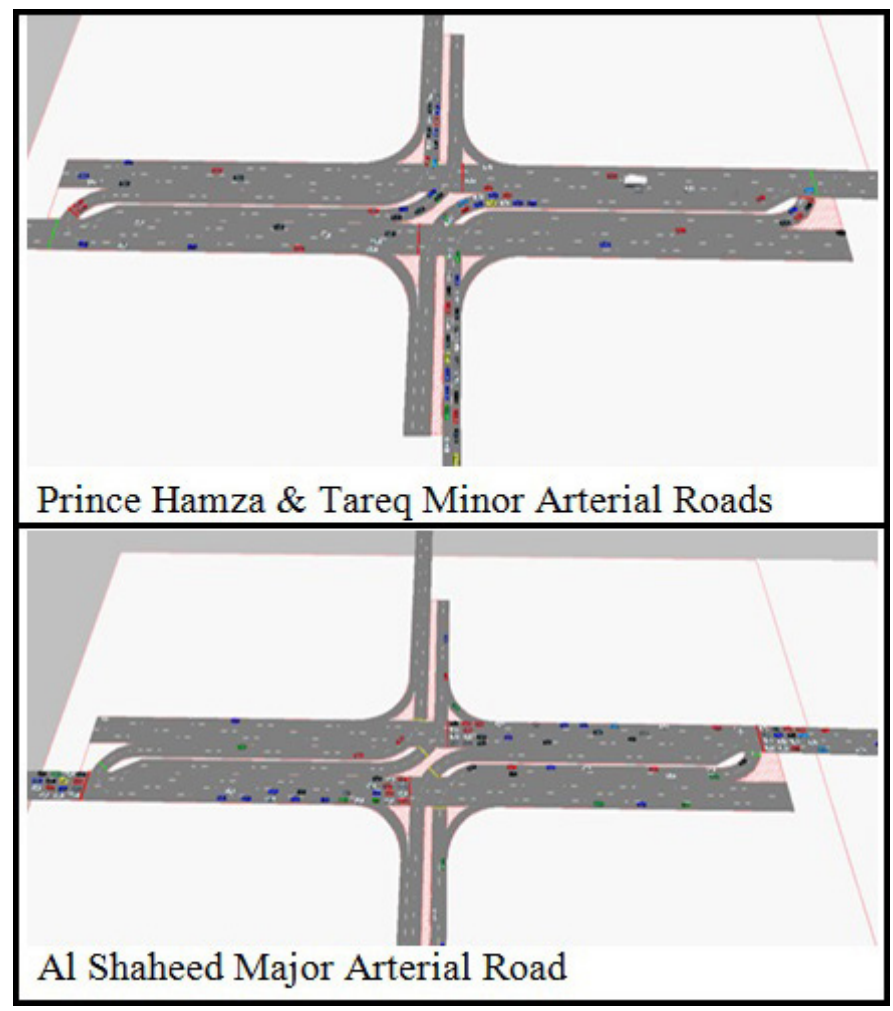

Fig. 4 VISSIM Simulation for the Proposed Superstreet Unconventional Intersection Design

\subsection{Model validation}

Model validation is usually conducted during the development of the simulation model to check the extent to which the model is representing the reality. There are two methods for simulation model validation; visual validation and statistical validation. The visual validation displays both real and simulation 
results side by side in an attempt to find the difference between them. While the statistical validation uses measures as goodness of fit, statistical tests, and the confidence intervals as validation keys. These keys are used to quantify the similarity between observed and simulated values (Toledot and Koutsopoulos, 2004; Hummer and Jagannathan, 2008; Naghawi, 2012)

The most popular goodness of fit measure is the root mean square percent error (RMSPE). The RMSPE is used to replicate the error as a percentile rate (Daiheng et al., 2004).

The RMSPE can be calculated using the following equation:

$$
R M S P E=\sqrt{\frac{1}{N} \sum_{1}^{N}\left(\frac{Y_{\text {sim }}-Y_{\text {observed }}}{Y_{\text {observed }}}\right)^{2}}
$$

(Daiheng et al., 2004)

Where:

$N$ is the number of simulation Runs.

$Y_{\text {sim }}$ is the simulation run throughput volume.

$Y_{\text {observed }}$ is the real throughput volume.

A total of thirty simulation runs using different random seed numbers were executed. The average simulated throughput volume on Al Shaheed road was found to be 5,920 vph, while the observed throughput volume on Al Shaheed road was 5,652 vph.

Based on Eq. (1) the RMSPE was found to be $0.87 \%$, this value is less than $15 \%$, which is the RMSPE threshold (Hourdakis et al., 2002). This indicates that the model replicates reality with high accuracy.

\section{Operational Evaluation}

In this paper, the aggregated results for the entire intersection were compared first. Then the disaggregated results for each movement were computed and compared.

\subsection{Aggregated Level of Analysis}

Table 3 shows the aggregated results of VISSIM analysis for the existing conventional four-legged signalized intersection and the proposed Superstreet unconventional intersection. The results include the average delay per vehicle (sec/veh.), LOS and the maximum queue length. These performance measures reflect traffic flow and discomfort levels caused to drivers on interrupted flow facilities. It can be seen that the intersection delay per vehicle was reduced by $70.44 \%$ on the proposed Superstreet compared to the conventional intersection design, as a result the intersection LOS was improved from $\mathrm{F}$ (forced conditions) to $\mathrm{C}$ (stable conditions). Also, the maximum queue length was reduced by almost $73 \%$ on the Superstreet when compared to the conventional intersection design.

Table 3 VISSIM Aggregated Analysis Results

\begin{tabular}{lccc}
\hline Intersection Design & Delay (sec/veh.) & LOS & Max Queue (m) \\
\hline Conventional & 87.3 & F & 510.2 \\
Superstreet & 25.8 & C & 141.1 \\
\hline
\end{tabular}

\subsection{Disaggregated Level of Analysis}

Table 4 shows the comparison results of the VISSIM analysis for the existing conventional four-legged signalized intersection and the proposed Superstreet unconventional intersection disaggregated by movement using the average delay per vehicle (sec/veh.) as a LOS measure. It can be seen that most traffic movements experienced 13 to 87 percent reduction in the average delay per vehicle when using the Superstreet intersection design, except for the traffic coming from the North, Tareq minor arterial road, and heading to the East, Al Shaheed major arterial road, on which the average delay per vehicle was increased by 25 percent. Also, the Table shows that the Superstreet intersection design significantly improved the LOS for all movements except for the North - East movement which remained the same as expected.

Table 4 Average Delay per Vehicle for Conventional and Superstreet Intersection Designs

\begin{tabular}{lccccc}
\hline \multirow{2}{*}{ Movement } & \multicolumn{2}{c}{ Conventional } & \multicolumn{2}{c}{ Superstreet } & Reduction \\
\cline { 2 - 4 } & $\begin{array}{c}\text { Avg. Delay } \\
\text { Sec/veh. }\end{array}$ & LOS & $\begin{array}{c}\text { Avg. Delay } \\
\text { Sec/veh. }\end{array}$ & LOS & $(\%)$ \\
\hline N-S & 40.5 & D & 35.2 & C & -13.09 \\
N-E & 38.3 & D & 47.9 & D & 25.07 \\
N-W & 4.5 & A & 0.6 & A & -86.67 \\
S-N & 68.6 & E & 47.2 & D & -31.20 \\
S-W & 103.2 & F & 47.9 & D & -53.59 \\
S-E & 1.2 & A & 0.6 & A & -50.00 \\
W-E & 73.6 & F & 37.2 & D & -49.47 \\
W-N & 244.5 & F & 34.5 & C & -85.89 \\
W-S & 18.3 & B & 10.4 & A & -43.17 \\
E-W & 112.9 & F & 17.8 & B & -84.23 \\
E-S & 290.3 & F & 37.2 & D & -87.19 \\
E-N & 60.7 & E & 16.6 & B & -72.65 \\
\hline & & & & & \\
\hline
\end{tabular}

Table 5 shows a comparison of the maximum queue length, disaggregated by movements, for the conventional and the Superstreet intersection designs. It can be seen that the Superstreet unconventional intersection design reduced the maximum queue length by 24 to 97 percent for almost all movements when compared to the conventional intersection design except for the North - East traffic, on which the maximum queue length was increased by almost 40 percent. This is consistent with the high average delay per vehicle for the North - East turning movement.

\section{Future Operational Evaluation}

So far, the Superstreet design has proven to improve traffic performance at the intersection under current traffic demand. The proposed Superstreet performance was also simulated and tested for future traffic demand after five years. An annual 
growth rate of $3 \%$ was used to predict the future traffic demand. This growth rate was based on forecasts performed by GAM for the use of long term transportation planning. Table 6 shows the aggregated results of the VISSIM models for the conventional four-legged signalized intersection and the proposed Superstreet unconventional intersection designs under the forecasted traffic demand. It can be seen that when using the Superstreet design, the average delay per vehicle will significantly be reduced by almost 76 percent, but the Superstreet intersection will operate under forced conditions with LOS F due to the intersection excessive delay. This means that the Superstreet unconventional intersection design is not appropriate for high traffic volumes.

Table 5 Maximum Queue Length for Conventional and Superstreet Intersection Designs

\begin{tabular}{lccc}
\hline Movement & $\begin{array}{c}\text { Conventional } \\
\text { Max Queue (m) }\end{array}$ & $\begin{array}{c}\text { Superstreet } \\
\text { Max Queue (m) }\end{array}$ & Reduction (\%) \\
\hline N-S & 18.6 & 14.1 & -24.19 \\
N-E & 18.6 & 26 & 39.78 \\
N-W & 14 & 14 & 0 \\
S-N & 79.7 & 33.4 & -58.093 \\
S-W & 79.7 & 33.4 & -58.09 \\
S-E & 0 & 0 & 0 \\
W-E & 161.9 & 11.8 & -92.71 \\
W-N & 161.9 & 9.6 & -94.07 \\
W-S & 54.4 & 9.6 & -82.35 \\
E-W & 446.6 & 11.8 & -97.36 \\
E-S & 446.6 & 11.8 & -97.36 \\
E-N & 427 & 11.8 & -97.24 \\
\hline
\end{tabular}

Table 6 Future Operational Evaluation Results

\begin{tabular}{lcc}
\hline Intersection Design & Delay (sec/veh.) & LOS \\
\hline Conventional & 299.4 & $\mathrm{~F}$ \\
Superstreet & 72.3 & $\mathrm{~F}$ \\
\hline
\end{tabular}

\section{Summary}

The primary aim of this study is to provide policy makers with an objective assessment on the possibility of implementing an unconventional arterial intersection design, the Superstreet, at one the heavily congested arterial intersections in Amman, Jordan. The signalized intersection of Tabarbour was selected to compare the operational efficiency of the current conventional signalized intersection with the proposed Superstreet intersection. Tabarbour intersection connects Al Shaheed major arterial road with Prince Hamza and Tareq minor arterial roads. The intersection currently suffers from interrupted traffic flow problems, long queue of vehicles, excessive delay and large amount of emissions. SYNCHRO microscopic simulation software was used for signal optimization of the current conventional intersection. Also VISSIM microscopic traffic simulation software was used to analyze and compare the Superstreet intersection design to the existing intersection. The performance measures considered were the average delay per vehicle, LOS and the maximum queue length. These performance measures reflect intersection efficiency and the comfort level of drivers on interrupted flow facilities.

In this paper, the aggregated results for the entire intersection were compared first. Then disaggregated results by movement were compared. On the aggregated level, it was found that the proposed Superstreet intersection design offers benefits over the conventional intersection design with its efficient two phase operations. It was found that the intersection delay per vehicle was reduced by 70 percent and the maximum queue length was reduced by almost 73 percent on the proposed Superstreet compared to the conventional intersection design, as a result the intersection LOS was improved from $\mathrm{F}$ to $\mathrm{C}$.

On the disaggregated level, the Superstreet witnessed a reduction of 13 to 87 percent in the average delay and a reduction of up to 97 percent in the maximum queue length when compared to the existing conventional intersection.

Finally, the proposed Superstreet performance was tested for future traffic demand after five years with an annual growth rate of $3 \%$. It was found that when using the Superstreet design, the average delay per vehicle will significantly be reduced by almost 76 percent, but the Superstreet intersection will operate under forced conditions with LOS F. This means that the Superstreet unconventional intersection design is not appropriate for high traffic volumes.

\section{References}

Bared, J., Kaisar, E. (2002). Median U-turn Design as an Alternative Treatment for Left Turns at Signalized Intersections. ITE Journal. 72(2), pp. 50-54.

Daiheng, N., Leonard II, J. D., Guin, A., Williams, B. M. (2004). Systematic Approach for Validating Traffic Simulation Models. Transportation Research Record: Journal of the Transportation Research Board. 1876, pp. 20-31.

https://doi.org/10.3141/1876-03

Federal Highway Administration. (2002). Guidelines for Selecting Signal Timing Software, Publication FHWA/TX-03/0-4020-P2. [Online]. Available from: http://citeseerx.ist.psu.edu/viewdoc/download?doi=10.1.1.536.6340\&rep=rep1\&type=pdf [Accessed: 20 th March 2016].

Federal Highway Administration. (2004). Signalized Intersections: Informational Guide, Publication FHWA-HRT-04- 091, pp. 219-276. [Online]. Available from: http://www.fhwa.dot.gov/publications/research/ safety/04091/04091.pdf [Accessed: 3rd March 2016].

Federal Highway Administration. (2010). Alternative Intersections/ Interchanges:Informational Report (AIIR), Publication FHWAHRT-09-060. [Online]. Available from: http://www.fhwa.dot.gov/publications/research/safety/09060/ [Accessed: 19th April 2016].

Federal Highway Administration. (2010). Superstreet Benefits and Capacities, Publication FHWA/NC/2009-05. [Online]. Available from: https://ntl. bts.gov/lib/37000/37800/37839/2009-06finalreport.pdf [Accessed: 19th March 2016]. 
Federal Highway Administration. (2014). Restricted Crossing U-turn Informational Guide, Publication FHWA-SA-14-070. [Online]. Available from: https://safety.fhwa.dot.gov/intersection/alter_design/ pdf/fhwasa14070_rcut_infoguide.pdf [Accessed: 27th March 2016].

Hochstein, J., Maze, T., Welch, T., Preston, H., Storm, R. (2009). The J-Turn Intersection: Design Guidance and Safety Experience. In: Transportation Research Board 88th Annual Meeting, Washington, D.C.

Hourdakis, J., Michalopoulos, P., Kottommannil, J. (2003). Practical Procedure for Calibration Microscopic Traffic Simulation Models. Transportation Research Record: Journal of the Transportation Research Board. 4167, pp. 130-139.

https://doi.org/10.3141/1852-17

Hummer, J., Jagannathan, R. (2008). An Updates on Superstreet Implementation and Research. In: 8th National Conference on Access Management, Transportation Research Board, Baltimore, MD.

Hummer, J., Reid, J. (1999). Unconventional Left-Turn Alternatives for Urban and Suburban Arterials- An Update. In: Transportation Research Circular E-C019: Urban Street Symposium Confirence Proceedings, pp. 28-30. Dallas, TX.

Hummer, J., Schroeder, B., Moon, J., Jagannathan, R. (2007). Recent Superstreet Implementation and Research. In: $3^{\text {rd }}$ Urban Street Symposium: Uptown, Downtown, or Small town: Designing Urban Street that Work, June 24-27, Seatlle, Washington, Transportation Research Board of National Academies, Washington, D.C.

Kim, T., Edara, P. K., Bared, J. (2007). Operational and Safety Performance of a Non-Traditional Intersection Design: The Superstreet. In: Transportation Research Board 86th Annual Meeting, Compendium of Papers CD-ROM, TRB, Washington, DC.
Minseok, K., Chang, G., Rahwanji, S. (2007). Unconventional Arterial Intersection Designs Initiatives. In: IEEE Conference on Intelligent Transportation Systems, Seattle, Washington.

Jae, M., Kim, Y., Kim, D., Lee, S. (2011). The Potential to Implement a Superstreet as an Unconventional Arterial Intersection Design in Korea. KSCE Journal of Civil Engineering. 15(6), pp. 1109-1114. https://doi.org/10.1007/s12205-011-1157-1

Municipality of Greater Amman. (2014). Traffic Operation Department reports. Naghawi, H., Idewu, W. (2014). Analysing Delay and Queue Length Using Microscopic Simulation for Unconventional Intersection Design Superstree. Journal of the South African Institution of Civil Engineers. 56(1), pp. 100-107.

Naghawi, H. (2012). Methodological Notes on Regional level Validation of Microscopic Traffic Simulation Model. Jordan Journal of Civil Engineering. 6(2).

Reid, J. (2004). Unconventional Arterial Intersection Designs, Management and Operational Strategies. Persons Brinckerhoff, New York, USA,

Reid, J., Hummer, J. (1999). Analyzing System Travel Time in Arterial Corridors with Unconventional Designs Using Microscopic Simulation. Transportation Research Record: Journal of the Transportation Research Board. 1678, pp. 208-215. https://doi.org/10.3141/1678-25

Toledot, T., Koutsopoulos, H. (2004). Statistical Validation of Traffic Simulation Models. Transportation Research Record: Journal of the Transportation Research Board. 1876, pp. 142-150. https://doi.org/10.3141/1876-15 